\title{
Corrigendum: Topography and Tilt at Volcanoes
}

\author{
Luke H. Marsden*, Jürgen W. Neuberg and Mark E. Thomas
}

School of Earth \& Environment, The University of Leeds, Leeds, United Kingdom

Keywords: topography, tilt, shear stress, pressure, numerical modeling, volcano

\section{A Corrigendum on}

\section{Topography and Tilt at Volcanoes}

by Marsden, L. H., Neuberg, J. W., and Thomas, M. E. (2019). Front. Earth Sci. 7:317. doi: 10.3389/feart.2019.00317

In the original article, there was an oversight, resulting in the previous work of Beauducel and Carbone (2015) and Albino et al. (2011) not being cited.

A correction has been made to Section 2. Influence of the Original Slope Angle, paragraph 3.

Inflation or deflation of a magma reservoir is commonly modeled analytically using a point source (Mogi, 1958), where the orientation of the displacement field at the surface varies with horizontal distance from the source. The point source approximation is valid for a spherical source where the source radius is small with respect to the distance from that source. Addressing the influence of topography, Cayol and Cornet (1998) showed that displacement produced by reservoir pressure is greater at lower elevation, where the surface is closer to the source. Delving further, Ronchin et al. (2015) found that the slope angle $\theta$ is a secondary control on the displacement. Through numerical modeling, they showed that the maximum displacement is produced where the surface is perpendicular to a line between the surface and source, where the exposure to the pressure source is greatest. We refer to the slope angle with the maximum exposure to the source at any point as $\theta_{\text {maxexp }}$, and the deviation from this angle as $\theta-\theta_{\text {maxexp. }}$. Hence, tilt generated by a point or spherical source is influenced by the slope angle. We vary this over a $90^{\circ}$ range around a point centered at $x=3 \mathrm{~km}, z=3 \mathrm{~km}$ (Figure 1C). We calculate $u$ and $w$ at each point along the slope using it's distance from the centre of a Mogi source $(x=0 \mathrm{~km}, z=-1 \mathrm{~km})$

$$
\left[\begin{array}{c}
u \\
v \\
w
\end{array}\right]=\alpha^{3} \Delta P \frac{1-v}{E_{\mathrm{m}}}\left[\begin{array}{c}
x / R^{3} \\
y / R^{3} \\
d / R^{3}
\end{array}\right],
$$

This article was submitted to

Volcanology

a section of the journal

Frontiers in Earth Science

Received: 31 January 2020 Accepted: 12 February 2020

Published: 03 March 2020

Citation:

Marsden $L H$, Neuberg JW and Thomas ME (2020) Corrigendum: Topography and Tilt at Volcanoes.

Front. Earth Sci. 8:46.

doi: 10.3389/feart.2020.00046 where $\Delta P$ is the pressure, $\alpha$ is the source radius, $d$ is the vertical distance between each point and the source center, $v$ is the Poisson's ratio and $E_{\mathrm{m}}$ is the Young's modulus. $v$ is the displacement in the $y$ direction, which is not used in this 2D example, but is considered in the 3D modeling later in section 5. The new slope angle can be computed as the derivative of the new coordinates for each point along the slope, $x+u$ and $z+w$. The tilt $\Delta \theta$ is then calculated as the change in slope angle. Beauducel and Carbone (2015) suggested that tilt induced by a spherical pressure source is greater where the slope of the edifice is steeper. However, we find that the tilt $\Delta \theta / \Delta \theta_{\max }$ is greatest where the surface is $45^{\circ}$ from the angle of maximum exposure, i.e., where $\theta-\theta_{\max e x p}=45^{\circ}$ (Figure 1C). In other words, no tilt is produced where the surface is parallel or perpendicular to the displacement field, and the highest tilt is generated where the surface is $45^{\circ}$ from this. This, unsurprisingly, is as previously shown for a purely horizontal displacement field. 
A correction has been made to Section 5. Real Topography, paragraphs 1 and 2 .

The 2D axisymmetric models in sections 3,4 are useful in demonstrating how exaggerated features of simplified topography can affect the tilt. However, it is important to consider whether the effect of real topography is significant or negligible. To do this, we present results of $3 \mathrm{D}$ deformation modeling, using $10 \mathrm{~m} \times 10 \mathrm{~m}$ digital elevation models (DEMs) of Tungurahua volcano, Ecuador and Soufrire Hills volcano, Montserrat (SHV), and compare how tilt varies spatially across both DEMs where topography is the only variable. We again asses the topographic effect on tilt induced by each of the sources described in section 1 . The mesh must be suitably fine such that the resolution of the DEM is matched. Beauducel and Carbone (2015) investigated the influence of real topography on tilt produced by a spherical pressure source. However, since they use a spatially variant mesh with a minimum element size of $200 \mathrm{~m}$, they thus do not consider the influence of local topography, which we show can significantly influence the tilt (section 4). Here, we use spatially variant triangular mesh across the entire DEM, to a distance of almost $8 \mathrm{~km}$ in $x$ and $y$ from the conduit, with a minimum element size of $\sim 1 \mathrm{~m}$ where the topography is most complex. The model is extrapolated to distance of $40 \mathrm{~km}$ in $x$ and $y$ and a depth of $50 \mathrm{~km}$, to ensure that

\section{REFERENCES}

Albino, F., Pinel, V., Massol, H., and Collombet, M. (2011). Conditions for detection of ground deformation induced by conduit flow and evolution. J. Geophys. Res. Solid Earth 116:B06201. doi: 10.1029/2010JB 007871

Beauducel, F., and Carbone, D. (2015). A strategy to explore the topographydriven distortions in the tilt field induced by a spherical pressure source: the case of Mt Etna. Geophys. J. Int. 201, 1471-1481. doi: 10.1093/gji/ ggv076

Cayol, V., and Cornet, F. H. (1998). Effects of topography on the interpretation of the deformation field of prominent volcanoesapplication to etna. Geophys. Res. Lett. 25, 1979-1982. doi: 10.1029/98GL5 1512 the deformation within the region that the DEM covers is not affected by the boundary constraints, described in section 3. A much coarser mesh (maximum element size $\sim 7 \mathrm{~km}$ ) is used for this extrapolation. We consider the maximum tilt for $\Delta \theta$, which is always positive and not necessarily radial to the source.

In defining the reference tilt, $\Delta \theta_{\mathrm{r}}$, we followed the common practice where topography is not considered. Therefore, $\Delta \theta_{\mathrm{AMP}}$ is the factor by which the modeled tilt is scaled when topography is considered relative to the common practice when it is not. For tilt generated by reservoir pressure, an analytical solution was used (Mogi, 1958) (Equation 7), taking the $x, y, z$ coordinates of each individual point across the mesh to calculate $\Delta \theta_{\mathrm{r}}$. For tilt produced by conduit pressure or shear stress, in the absence of an available analytical solution, we obtain $\Delta \theta_{\mathrm{r}}$ from $2 \mathrm{D}$ axisymmetric models using a constant slope, based on the average dip angle radially away from the summit for each edifice. This mimics the approach of Albino et al. (2011), who represent topography using only this first-order approximation. The computation of this average dip angle, and a full description of these 2D axisymmetric models, is included in the Supplementary Material, Section S1.

The authors apologize for this oversight and state that this does not change the scientific conclusions of the article in any way. The original article has been updated.

Mogi, K. (1958). Relations between the eruptions of various volcanoes and the deformations of the ground surfaces around them. Bull. Earthq. Res. Inst. Univ. Tokyo 36, 99-134.

Ronchin, E., Geyer, A., and Martí, J. (2015). Evaluating topographic effects on ground deformation: insights from finite element modeling. Surv. Geophys. 36, 513-548. doi: 10.1007/s10712-015-9325-3

Copyright (c) 2020 Marsden, Neuberg and Thomas. This is an open-access article distributed under the terms of the Creative Commons Attribution License (CC BY). The use, distribution or reproduction in other forums is permitted, provided the original author(s) and the copyright owner(s) are credited and that the original publication in this journal is cited, in accordance with accepted academic practice. No use, distribution or reproduction is permitted which does not comply with these terms. 